\title{
Comparison on Surface Roughness and Its Effect on Bonding between Conventional Bur and Laser Cut Cavities: An in vitro Study
}

\author{
${ }^{1}$ Preethi Varadan, ${ }^{2}$ Lakshmi Balaji, ${ }^{3}$ Deivanayagam Kandaswamy
}

\begin{abstract}
Buccal surfaces of human extracted molars were obtained and divided into three groups for cavity preparation. Class $\mathrm{V}$ cavities were prepared using diamond bur for Group 1, tungsten carbide bur for Group 2, and Er,Cr:YSGG laser for Group 3. The surface roughness was measured using a 3D noncontact profilometer. The samples were subdivided into subgroups $A$ and $B$, where subgroup $B$ underwent additional acid-etching procedure. The temperature rise during cavity preparation was recorded using a digital thermostat. The samples were then restored with composite resin following application of bonding agent and light cured for 20 seconds for bond strength evaluation under Universal Testing Machine at a cross speed of $0.5 \mathrm{~mm} /$ minutes. The data obtained were finally statistically analyzed. On surface roughness evaluation, laser group (G3) produced maximum surface roughness when compared to conventional bur groups (G1 and G2). On depth of surface roughness evaluation, additional acid etching increased surface roughness of all three groups with laser group (subG3B) followed by acid etching exhibiting maximum surface roughness. On bond strength evaluation, diamond group (G1) exhibited increased bond strength when compared to laser (G3) and tungsten carbide group (G2). On thermal change estimation, all the three groups (G1, G2, and G3) produced minimal temperature rise which was below 5.5. Despite increased surface roughness produced by laser, conventional diamond bur (G1) produced highest bond strength when compared to laser (G3) and tungsten carbide groups (G2).
\end{abstract}

Keywords: Dental burs, Digital thermostat, Laser, 3D noncontact profilometer.

How to cite this article: Varadan P, Balaji L, Kandaswamy D. Comparison on Surface Roughness and Its Effect on Bonding between Conventional Bur and Laser Cut Cavities: An in vitro Study. Int J Laser Dent 2015;5(1):6-11.

Source of support: Nil

Conflict of interest: None

\footnotetext{
${ }^{1}$ Senior Lecturer, ${ }^{2}$ Professor, ${ }^{3}$ Dean, Professor and Head

${ }^{1-3}$ Department of Conservative Dentistry and Endodontics Faculty of Dental Sciences, Sri Ramachandra University Chennai, Tamil Nadu, India

Corresponding Author: Preethi Varadan, Senior Lecturer Department of Conservative Dentistry and Endodontics, Faculty of Dental Sciences, Sri Ramachandra University, Chennai Tamil Nadu, India, Phone: +919884185282, e-mail: divya varadan@gmail.com
}

\section{INTRODUCTION}

Success of any restoration mainly depends on adhesion to enamel and dentin. ${ }^{1}$ In dentistry, among four adhesion mechanisms, mechanical adhesion still proves to play a prime role in enhancing retention of restoration. ${ }^{2}$ Mechanical adhesion is achieved by interlocking of the adhesive with irregularities in the surface of the substrate (tooth). ${ }^{2}$ It is presumed that surface roughness and irregularities promote the wettability by increasing surface area and that the bond between the adherend surface and the adhesive will be subsequently stronger. ${ }^{3}$

Mechanical retention was mainly achieved by conventional burs, such as diamond burs and tungsten carbide burs which were commonly used for cavity preparations. ${ }^{4}$ However, cavity preparation using rotary burs creates an amorphous layer of organic and inorganic debris, known as smear layer, on the surface of the enamel which interferes on bonding of the adhesive agents to enamel. ${ }^{5}$

Cavity preparation is usually followed by acid etching with $37 \%$ phosphoric acid for 15 seconds. Enamel etching with acid removes $10 \mu \mathrm{m}$ of surface enamel and creates microporous layer which is 5 to $50 \mu \mathrm{m}$ deep, thereby facilitating formation of resin tags within enamel. ${ }^{6}$

Laser technology has attained popularity over the recent years, and its uses in restorative dentistry includes removal of carious tissue, reduction in dentin hypersensitivity, conditioning of enamel and dentin for adhesive systems, caries prevention in pits, and fissures. Er,Cr:YSGG lasers are group of Erbium laser systems, that operates at a wavelength of $2.780 \mu \mathrm{m} .{ }^{8}$ Erbium lasers produced similar surface to that of conventional phosphoric acid etching. ${ }^{9}$ Erbium lasers with appropriate parameters selectively removes hydroxyapatite crystals from enamel producing surface irregularities that could enhance the micromechanical retention. ${ }^{10}$

Recently, three dimensional (3D) optical laser profilometer has been widely used as it provides a noncontact, nondestructive, quick quantitative measurement for surface roughness. ${ }^{11}$ It permits multiple descriptions of surface roughness profile of composite resins that is possible beyond two dimensional (2D) surface profilometer. ${ }^{12,13}$ Canabarro et al (2009) ${ }^{14}$ studied comparative topographic analysis of titanium surfaces using $3 \mathrm{D}$ and 
2D profilometers and concluded that 3D profilometer was more appropriate analytical method than $2 \mathrm{D}$ profilometer due to its ability to describe surface organization.

Conventional burs produce more heat during cavity preparation in comparison to laser systems and induce more deleterious effects on pulp than lasers. To confirm this, temperature rise during cavity preparation using both conventional burs and laser systems were recorded using a digital thermostat. ${ }^{15,16}$

Laser-prepared cavities with or without acid etching on improving bond strength of composite resin restorations have always been controversial. ${ }^{17-20}$

Thus, the aim of current study is;

- To compare the surface roughness of the cavities prepared using conventional burs and laser systems and to evaluate whether phosphoric acid etching, following laser, alters the surface morphology or not.

- To estimate the thermal changes occurring during cavity preparation using laser and bur.

- To analyze the bond strength of composite resin to dentin to cavities prepared using laser and conventional burs.

\section{MATERIALS AND METHODS}

\section{Sample Preparation}

Twenty-eight freshly removed human molars were obtained. The teeth were stored in $0.5 \%$ chloramine solution at $4^{\circ} \mathrm{C}$ to prevent bacterial overgrowth. Teeth with caries, restorations, hypoplastic areas, cracks, or gross irregularities were not included. The buccal surfaces of each crown were ground with 500 grit abrasive paper under running water in order to provide uniform flat surfaces of enamel. The samples were divided randomly into four groups (Table 1). The groups were prepared using (1) Medium grit diamond bur, (2) tungsten carbide bur (3) Er,Cr:YSGG laser alone, and (4) Er,Cr:YSGG ablation plus conventional acid-etching procedure with $37 \%$ phosphoric acid.

Laser group was prepared using Er,Cr:YSGG laser system (Waterlase Millennium ${ }^{\mathrm{TM}}$, Biolase Technologies Inc., San Clemente, CA, USA) emitting photons at a

Table 1: The groups and their subclassification depending on etching and armamentarium used

\begin{tabular}{lll}
\hline $\begin{array}{l}\text { Experimental } \\
\text { groups }\end{array}$ & Subgroups & Armamentarium used \\
\hline 1 & A - etching & Medium grit \\
& B - without etching & Diamond bur \\
2 & A - etching & Tungsten carbide bur \\
& B - without etching & \\
3 & A - etching & Er,Cr:YSGG laser \\
& B - without etching & \\
\hline
\end{tabular}

wavelength of $2.78 \mu \mathrm{m}$, pulsed with a time period between 140 and $200 \mu \mathrm{m}$. The output power varied from 0 to $6 \mathrm{~W}$. The beam spot size was $0.442 \mathrm{~mm}^{2}$ with the use of a $750 \mu \mathrm{m}$ diameter fiber at the distance of 2 to $3 \mathrm{~mm}$. Irradiation was carried out according to manufacturer's instructions. During initial cavity preparation, laser irradiation was performed in a contact mode for removing enamel with a focused beam of $6 \mathrm{~W}\left(67.9 \mathrm{~J} / \mathrm{cm}^{2}\right)$ at $90 \%$ air pressure level and $75 \%$ water level and $20 \mathrm{~Hz}$ frequency. As the enamel removal was progressing near dentin, the power was reduced to $3 \mathrm{~W}\left(33.9 \mathrm{~J} / \mathrm{cm}^{2}\right)$ at $70 \%$ air level and $20 \%$ water level. The cavities were finished carefully in a noncontact irradiation mode.

In subgroups $1 \mathrm{~B}, 2 \mathrm{~B}$, and $3 \mathrm{~B}$ cavity preparation was followed by additional conventional etching procedure, with $37 \%$ phosphoric acid for a period of 15 seconds, while in subgroups 1A, 2A, and 3A only cavity preparation was done, no etching procedure was carried out.

\section{Thermal Change Estimation}

The biggest root of tooth sample was amputated and thermocouple was inserted into the pulp chamber. The digital thermostat was fixed by red wax in the pulp chamber, and the temperature was recorded. The red wax was used to prevent the water used as a coolant during cavity preparation from influencing the temperature readings. Within the chamber, the thermostat was placed adjacent to the irradiated area.

\section{Surface Roughness Analysis}

The surface roughness of the samples was examined using a 3D noncontact profilometer (Talysurf CCI Lite System, Taylor Hobson Ltd, Leicester, UK) at 50× magnification.

\section{Bond Strength Assessment}

After surface roughness evaluation, all the samples were etched with 37\% phosphoric acid for 15 seconds (except Group 4 which was already etched) and rinsed with distilled water for the same time. Bonding agent (Meta P \& Bond, Meta BioMed, Korea) was applied and light cured for 10 seconds. The samples were then restored with light-cured composite resin and light cured for 20 seconds. Samples were stored in distilled water at $37^{\circ} \mathrm{C}$ for 24 hours prior to being subjected to the microtensile bond strength test. A Universal Testing Machine (Instron 3382, Canton, MA, USA) was used at a crosshead speed of $0.5 \mathrm{~mm} / \mathrm{minutes}$. The data obtained in newton $(\mathrm{N})$ were converted to megapascals (MPa) using the mentioned formula below:

$1 \mathrm{MPa}=1.0 \times 10^{-6} \times \mathrm{N} / \mathrm{m}^{2}$ 


\section{Statistical Analysis}

The data collected was analyzed with Statistical Package for the Social Sciences (SPSS) 16.0 version. To describe about the data descriptive statistics, mean and standard deviation were used. For bivariate analysis, MannWhitney test was used in case of independent samples and Wilocoxon signed-rank test was used in case of paired samples. For mutlivariate analysis, KruskalWalli's test was used. In the above statistical tool the probability value $\mathrm{p}=0.05$ is considered as significant level.

\section{RESULTS}

On surface roughness evaluation, Kruskal-Walli's analysis showed Group 3 (laser group) exhibited maximum surface roughness when compared with Group 2 (diamond bur) and Group 1 (tungsten carbide bur). Group 1 showed least average surface roughness among other two groups. On comparison of surface roughness among the subgroups A and $\mathrm{B}, \mathrm{Man}-$ Whitney analysis and Wilcoxon signed-rank test showed subgroups $1 \mathrm{~B}, 2 \mathrm{~B}$, and $3 \mathrm{~B}$ (etched groups) produced higher surface roughness in comparison to subgroups 1A, 2A, and 3A (nonetched groups) (Table 2).

On surface roughness depth evaluation, Group 3 showed increased depth of surface roughness when compared to both the groups, and Group 1 showed least depth of surface roughness. Among the subgroups, subgroups $1 \mathrm{~B}, 2 \mathrm{~B}$, and $3 \mathrm{~B}$ (etched groups) exhibited deeper surface roughness in comparison to subgroups $1 \mathrm{~A}, 2 \mathrm{~A}$, and $3 \mathrm{~A}$ (nonetched groups) (Table 3).

On microtensile bond strength evaluation, diamond group (G1) showed highest bond strength followed by

Table 2: Mean and standard deviation for roughness parameters

\begin{tabular}{llll}
\hline \multirow{2}{*}{ Groups } & \multicolumn{2}{l}{ Average surface roughness (Ra) } \\
\cline { 3 - 4 } & Subgroups & Mean & Standard deviation \\
\hline 1 & 1A & 0.531 & 0.244 \\
& 1B & 0.537 & 0.137 \\
2 & 2A & 0.206 & 0.621 \\
3 & 2B & 0.216 & 0.504 \\
& 3A & 0.595 & 0.103 \\
& 3B & 1.70 & 0.533 \\
\hline
\end{tabular}

Table 3: Mean and standard deviation for roughness depth parameters

\begin{tabular}{llll}
\hline & & \multicolumn{2}{c}{ Surface roughness depth $(R v)$} \\
\cline { 3 - 4 } Groups & Subgroups & Mean & Standard deviation \\
\hline 1 & 1A & 1.38 & 0.88 \\
& 1B & 1.62 & 0.43 \\
2 & 2A & 0.62 & 0.20 \\
& 2B & 0.63 & 0.19 \\
3 & 3A & 1.85 & 0.38 \\
& 3B & 3.96 & 1.23 \\
\hline
\end{tabular}

Table 4: Microtensile bond strength

\begin{tabular}{lll}
\hline Groups & $\begin{array}{l}\text { Mean }\left(\times 10^{-3}\right) \\
(\mathrm{MPa})\end{array}$ & $\begin{array}{l}\text { Standard deviation } \\
\left(\times 10^{-4}\right)(\mathrm{MPa})\end{array}$ \\
\hline Diamond (G1) & 0.410 & 0.08117 \\
Tungsten carbide (G2) & 0.335 & 0.08114 \\
Laser (G3) & 0.367 & 0.138 \\
\hline
\end{tabular}

laser group (G3) and tungsten carbide group (G2) respectively (Table 4).

On temperature rise evaluation using digital thermostat both diamond (G1) and tungsten carbide preparation (G2) showed 3 to $4^{\circ} \mathrm{C}$ rise from room temperature, whereas laser preparation (G3) showed only $2^{\circ} \mathrm{C}$ rise from room temperature

\section{DISCUSSION}

One of the most desirable properties of a restorative material is adhesion to dental substrate as it prevents fracture of the material and marginal leakage. These two are the most prominent factors for failure of the restoration subsequently. ${ }^{21}$

Surface roughness plays as the prime criterion in enhancing adhesion of restoration by increasing the surface area and improving the wettability properties. ${ }^{3}$ It is measured in $\mathrm{Ra}$ (arithmetic mean) and $\mathrm{Rv}$ (depth of surface roughness) values. ${ }^{3}$ Though scanning electron microscope (SEM), transmission electron microscope (TEM), mechanical profilometer, light microscope, and atomic force microscope have been used for measuring surface roughness values, the inability of the sensor needles of these devices to penetrate all the irregularities have brought a 3D profilometer into focus. This has the distinct advantage of being noncontact, nondestructive, and quick quantitative measurement for surface roughness providing multiples descriptions of surface roughness profiles beyond the ability of 2D surface profilometer. Hence, this methodology has been used in the current study. ${ }^{22-24}$

Diamond and tungsten carbide burs have been used commonly in restorative procedures for their excellent mechanical retentive qualities in cavity preparation. ${ }^{4}$ Numerous studies have compared the surface morphology in cavities prepared using diamond and tungsten carbide burs and concluded that more surface roughness was evident in diamond bur preparation in comparison to tungsten carbide preparation. ${ }^{2,5,25}$ The present study, confirming the above literatures also exhibited more surface roughness in diamond groups (1A and $1 \mathrm{~B})$ than in tungsten carbide groups (2A and 2B).

However, although diamond produced greater surface roughness than tungsten carbide bur, it had a demerit of producing thick smear layer which might hinder bonding of restoration to enamel surface. ${ }^{26,27}$ In order to eliminate 
this factor, concept of acid-etching enamel was proposed by Buonocore in 1955, which not only removed the smear layer but also improved mechanical retention by selectively exposing hydroxyapatite formation facilitating resin penetration to a depth of 6 to $12 \mu \mathrm{m} .^{28}$

Ability of hard tissue removal without smear layer production has brought lasers into modern dentistry replacing these conventional burs. ${ }^{8,29}$ Among various lasers, Erbium lasers (high-intensity lasers) are the most efficient and safest system of lasers, showing similarities to acid-etched enamel. ${ }^{8,29}$

Er:Cr:YSGG lasers cut dental hard tissue with the help of its laser-powered hydrokinetic system at infrared wavelength of 2.7 to $3 \mu \mathrm{m} .{ }^{30}$ Microexplosions during laser ablation produces imbricate-patterned surface with an evidently rough aspect without smear layer production. ${ }^{30}$

Although laser produces greater surface roughness, it has disadvantage of increased microleakage. To overcome this, additional phosphoric acid etching was recommended which decreased the microleakage and increased bond strength. ${ }^{16,31-33}$ Robles et $\mathrm{al}^{34}$ compared conventional bur and Er:YAG laser in Class $\mathrm{V}$ cavities with or without acid etching and observed higher degree of microleakage without additional etching procedure. Ceballos et $\mathrm{al}^{31}$ found that laser ablation of enamel alone was not sufficient to prevent microleakage in occlusal enamel compared to cavities that were acid-etched. Pires et $\mathrm{al}^{8}$ evaluated the shear bond strength values (SBS) of various dental adhesives on Er:YAG lasers, prepared enamel, and concluded that acid etching increased adhesion in laser-treated enamel. Thus lasers were brought into focus in cavity preparation to overcome the disadvantages of conventional burs.

The current study has compared the surface roughness created using both conventional burs and laser and found out that laser produced more surface roughness when compared to conventional burs.

As acid-etching procedure was recommended in laser-prepared cavities by previous studies, ${ }^{31,34}$ acidetching procedure was performed for the mentioned three groups $(1 \mathrm{~B}, 2 \mathrm{~B}$, and $3 \mathrm{~B})$, and our study confirmed the known fact that laser with additional etching procedure (Group 3B) produced maximum surface roughness in comparison to other groups using 3D noncontact, nondestructive profilometer.

During cavity preparation, the temperature rise in the pulp chamber was also recorded in the present study. Laser preparation showed only $2^{\circ} \mathrm{C}$ rise in temperature, whereas diamond and tungsten carbide burs showed 3 to $4^{\circ} \mathrm{C}$, both were below the critical level (5.5) which could cause any detrimental effects to the pulp. ${ }^{19,20}$ Hence, the present study concluded that both conventional burs and lasers are safe for cavity preparation.

Other than surface roughness evaluation, the current study also aimed on evaluating the influence of surface roughness on bond strength to enamel surfaces. Various studies on bond strength evaluation had showed similar or greater bond strength values of laser-irradiated cavities when compared to bur cut cavities. Wanderley et $\mathrm{al}^{32}$ assessed the influence of Er:YAG laser energy on the shear bond strength of a total etch adhesive system to lased enamel of primary teeth and concluded that bond strengths recorded after laser irradiation were statistically superior to those yielded by the acid-etched control group. Keller and Hibst ${ }^{33}$ analyzed the influence of laser on enamel bonding of composite resin and found best results in laser-conditioned enamel rather than conventional acid-etching procedure.

However, laser group in current study exhibited reduced bond strength in comparison with diamond group. De Munck et $\mathrm{al}^{35}$ assessed the hypotheses that tooth substrate prepared either by Er:YAG laser or by diamond bur is equally responsive to adhesive procedures and observed that cavities prepared by laser appeared less amenable to adhesive procedures than conventional bur-cut cavities. Esteves-Oliveira and Zezell ${ }^{11}$ evaluated the tensile bond strength of a self-etching primer system to enamel and dentin surfaces treated with Er:YAG and Er,Cr:YSGG lasers and conventional bur and observed that bond strength for both laser-irradiated groups were statistically lower than for the bur-cut group.

The possible reasons could be as follows:

- Laser irradiation forms acid-resistant layer due to loss of carbonates and formation of new hydroxyapatitelike crystals which compromises bonding due to reduced etching effectiveness. They have been knowingly used in dental caries prevention for this acid-resistant layer. But this hypothesis cannot be considered in this study, as laser showed that on additional acid etching, depth of surface roughness is increased. Thus the surface roughness alone may not be a contributing factor, and the quality of the enamel left behind may also play a major factor for bonding of restoration to enamel. ${ }^{36,37}$

- During cavity preparation, laser works by causing microexplosions in enamel surface, leading to formation of microcracks. However, these crack propagations are not uniform and their depth is variable. Thus enamel surface becomes weaker, and this may be the main reason for weaker bonding of the restoration. ${ }^{37}$

- Diamond, at the same time, produces adequate surface roughness without drastic shift in minerals and crack propagations. 
- Even though depth of penetration of acid was less in diamond group which could have been utilized for smear layer removal, still the quality of enamel surface left behind, and surface roughness could have contributed to the bond strength of restoration to enamel surface in diamond group (Group 1B).

\section{CONCLUSION}

Within the limitations of the study, the bond strength values differed notably among the conventional bur systems and laser systems. Although laser produced greater surface roughness, conventional diamond burs exhibited better bond strength when compared to laser group. Both the laser and conventional burs systems may be considered safe due to their minimal detrimental effects on pulp during cavity preparation.

\section{REFERENCES}

1. Kameyama A, Oishi T, Sugawara T, Hirai Y. Microtensile bond strength of indirect resin composite to resin coated dentin: interaction between diamond bur roughness and coating material. Bull Tokyo Dent Coll 2009 Feb;50(1):13-22.

2. Roberson T. Sturdevant's art and science of operative dentistry. 5th ed. St. Louis (MO): Mosby; 2006.

3. Al-Omari WM, Mitchell CA, Cunningham JL. Surface roughness and wettability of enamel and dentin surfaces prepared with different dental burs. J Oral Rehabil 2001 Jul;28(7):645-650.

4. Bhagwat S, Mehta D. Bur .... no more: non rotary methods of cavity preparation. Sci J 2008;2:1-5.

5. Semeraro S, Mezzanzanica D, Spreafico D. Effect of different bur grinding on the bond strength of self-etching adhesives. Oper Dent 2006 May-Jun;31(3):317-323.

6. Ramya R. Clinical operative dentistry; Principles and practice. EMMESS Medical publishers, 1st ed. Bangalore (Karnataka): 2007.

7. Oliveira CS, Ramalho KM, Bello-Silva MS. The use of lasers in restorative dentistry: truths and myths. Braz Dent Sci 2012;15(3):3-15.

8. Pires PT, Ferreira JC, Oliveira SA, Azevedo AF. Shear bond strength and SEM morphology evaluation of different dental adhesives to enamel prepared with Er:YAG laser. Contemp Clin Dent 2013 Jan;4(1):20-26.

9. Gokce B. Effect of Er:YAG laser irradiation on dental hard tissues and all-ceramic materials: SEM evaluation. In: Viacheslav K, editor. Scanning electron microscopy. New York (NY): In Tech; 2012. p. 179-212.

10. Eliades T, Gioka C, Eliades G. Enamel surface roughness following debonding using two resin grinding methods. Eur J Orthod 2004 Jun;26(3):333-338.

11. Esteves-Oliveira M, Zezell DM. Bond strength of self-etching primer to bur cut, Er,Cr:YSGG, and Er:YAG lased dental surfaces. Photomed Laser Surg 2007 Oct;25(5):373-380.

12. Kakaboura A, Fragouli M. Evaluation of surface characteristics of dental composites using profilometry, scanning electron, atomic force microscopy and gloss-meter. J Mater Sci Mater Med 2007 Jan;18(1):155-163.

13. de Carvalho RC, de Freitas PM, Otsuki M. Micro-shear bond strength of Er:YAG-laser-treated dentin. Lasers Med Sci 2008 Apr;23(2):117-124.
14. Canabarro A, Figueiredo F, Paciornik S. Two- and threedimensional profilometer assessments to determine titanium roughness. Scanning 2009 Jul-Aug;31(4):174-179.

15. Lin S, Caputo AA, Eversole LR. Topographical characteristics and shear bond strength of tooth surfaces cut with a laser-powered hydrokinetic system. J Prosthet Dent 1999 Oct;82(4):451-455.

16. Ferriera LS, Apel C, Francii C. Influence of etching time on bond strength in dentin irradiated with Erbium lasers. Lasers Med Sci 2010 Nov;25(6):849-854.

17. Rizoiu I, Kohanghadosh F, Kimmel AI. Pulpal thermal responses to an erbium, chromium: YSGG pulsed laser hydrokinetic system. Oral Surg Oral Med Oral Pathol Oral Radiol Endod 1998 Aug;86(2):220-223.

18. Cavalcanti BN, Lage-Marques JL, Rode SM. Pulpal temperature increases with Er:YAG laser and high-speed handpieces. J Prosthet Dent 2003 Nov;90(5):447-451.

19. Al-Qaradaghi TS, Mahmood AS, Dayem RN. The efficacy of Er:YAG laser on intrapulpal temperature rise of class $\mathrm{V}$ cavity preparation. Iraqi J Laser 2011;10(1):9-14.

20. Wang X, Matsumoto K. Pulpal response to cavity preparation by Er,Cr:YSGG laser: an in vivo study. J Oral Laser Appl 2005 Jan;5(1):23-30.

21. Davari A, Sadeghi M, Bakhshi H. Shear bond strength of an etch-and-rinse adhesive to Er:YAG laser- and/or phosphoric acid-treated dentin. J Dent Res Dent Clin Dent Prospects 2013;7(2):67-73.

22. Sakrana AAES, Abouelatta OB. Surface roughness evaluation of polished composite using three dimension profilometry. Int Chin J Dent 2004;4:85-91.

23. Atali PY, Topbasi FB. The effect of different bleaching methods on the surface roughness and hardness of resin composites. J Dent Oral Hyg 2011;3:10-17.

24. Uppal M, Ganesh A, Balagopal S, Kaur G. Profilometric analysis of two composite resins' surface repolished after tooth brush abrasion with three polishing systems. J Conserv Dent 2013 Jul;16(4):309-313.

25. Rocha PI, Borges AB, Rodrigues JR. Effect of dentinal surface preparation on bond strength of self-etching adhesive systems. Braz Oral Res 2006 Jan-Mar;20(1):52-58.

26. Peerzada F, Yiu CK, Hiraishi N. Effect of surface preparation on bond strength of resin luting cements to dentin. Oper Dent 2010 Nov-Dec;35(6):624-633.

27. Jung M, Eichelberger K, Klimek J. Surface geometry of four nanofiller and one hybrid composite after one-step and multiple-step polishing. Oper Dent 2007 Jul-Aug;32(4): 347-355.

28. Luddin N, Ngo H, McIntyrec J, Abbott J. Comparison study of ultrastructure and adhesive properties of enamel prepared by Er:YAG laser and conventional bur. J Oral Laser Appl 2006;6:89-94.

29. Obeidi A, Liu PR, Ramp LC. Acid-etch interval and shear bond strength of Er,Cr:YSGG laser-prepared enamel and dentin. Lasers Med Sci 2010 May;25(3):363-369.

30. Ergucu Z, Celik EU, Unlu N. Effect of Er,Cr:YSGG laser on the microtensile bond strength of two different adhesives to the sound and caries-affected dentin. Oper Dent 2009 JulAug;34(4):460-466.

31. Ceballos L, Osorio R, Toledano M. Microleakage of composite restorations after acid or Er-YAG laser cavity treatments. Dent Mater 2001 Jul;17(4):340-346. 
32. Wanderley RL, Monghini EM, Pecora JD, Palma-Dibb RG, Borsatto MC. Shear bond strength to enamel of primary teeth irradiated with varying Er:YAG laser energies and SEM examination of the surface morphology: an in vitro study. Photomed Laser Surg 2005 Jun;23(3):260-267.

33. Keller U, Hibst R. Effect of Er:YAG on enamel bonding of composite resin. SPIE Proc 1993 Jul 21;1880:127-133.

34. Robles F, Ramos A, Zezell D, Eduardo CE. SEM and EDX evaluation of microleakage in cavities prepared with Er:YAG laser. J Dent Res 2000;79(5):1098.
35. De Munck J, Van Meerbeek B, Yudhira R. Micro-tensile bond strength of two adhesives to Erbium:YAG-lased vs bur-cut enamel and dentin. Eur J Oral Sci 2002 Aug;110(4):322-329.

36. Kim JH, Kwon OW, Kim HI, Kwon YH. Acid resistance of erbium-doped yttrium aluminum garnet laser-treated and phosphoric acid-etched enamels. Angle Orthod 2006 Nov;76(6):1052-1056.

37. Cardoso MV, De Munck J, Coutinho E. Influence of Er,Cr:YSGG laser treatment on microtensile bond strength of adhesives to enamel. Oper Dent 2008 Jul-Aug;33(4):448-455. 